\title{
Narcissism, Self-Esteem, and the Positivity of Self-views: Two Portraits of Self-Love
}

\author{
W. Keith Campbell \\ University of Georgia \\ Eric A. Rudich \\ University of North Carolina, Chapel Hill \\ Constantine Sedikides \\ University of Southampton
}

The authors hypothesized that both narcissism and high selfesteem are associated with positive self-views but each is associated with positivity in different domains of the self. Narcissists perceive themselves as better than average on traits reflecting an agentic orientation (e.g., intellectual skills, extraversion) but not on those reflecting a communal orientation (e.g., agreeableness, morality). In contrast, high-self-esteem individuals perceive themselves as better than average both on agentic and communal traits. Three studies confirmed the hypothesis. In Study 1 , narcissists rated themselves as extraverted and open to experience but not as more agreeable or emotionally stable. High-selfesteem individuals rated themselves highly on all of these traits except openness. In Study 2, narcissists (but not high-self-esteem individuals) rated themselves as better than their romantic partners. In Study 3, narcissists rated themselves as more intelligent, but not more moral, than the average person. In contrast, highself-esteem individuals viewed themselves as more moral and more intelligent.

Two constructs that continue to command the attention of social and personality psychologists are narcissism and self-esteem. These two constructs are partially overlapping. First and foremost, both narcissists and high-self-esteem individuals have a high self-opinion: They are said to like-and even love-themselves. Indeed, this similarity may explain why the two variables correlate positively, as a recent meta-analysis indicated ( $r=.29$, $k=11, n=2,963, p<.001$ ) (Campbell, 2001). However, narcissism and high self-esteem also have critical differences. Of particular note are the interpersonal implications of these traits. Narcissism is rather detrimental to interpersonal relationships, whereas self-esteem may be beneficial. Perhaps this is why in our culture narcissism is considered to be a curse, whereas high self-esteem is regarded as a boon.

Our objective in the present research is to explore the bases of the positive self-views that narcissists and' highself-esteem (HSE) individuals have. In particular, we wish to uncover those aspects of the self in which narcissists and HSE individuals hold themselves in the highest (and lowest) regard. To presage our hypotheses: We predict that even though both narcissists and HSE individuals have positive self-views, these groups hold self-views that are distinct in theoretically meaningful ways. Specifically, narcissists' self-conceptions reflect agentic (but not communal) concerns and HSE individuals' self-conceptions reflect both agentic and communal concerns. That is, narcissists manifest an egoistic bias, whereas HSE individuals display both an egoistic and a moralistic bias. Narcissists perceive themselves as intelligent and outgoing but not as caring or conscientious. HSE individuals perceive themselves as both intelligent and caring.

Our research paradigm is derived primarily from work on the better-than-average effect (Alicke, 1985; Alicke, Klotz, Breitenbecher, Yurak, \& Vredenberg, 1995). We ask participants to compare themselves to the average other on a range of theoretically relevant traits. We rely on two widely used personality instruments, the Narcissistic Personality Inventory (NPI) (Raskin \& Hall, 1979)

Authors' Note: We would like to thank Ahmie Polak for assistance in conducting these studies. We would also like to thank Roy Baumeister, Dawn Dhavale, and Katie Vohs for helpful comments. Correspondence concerning this article should be addressed to W. Keith Campbell, Department of Psychology, University of Georgia, Athens, GA 30602 3013; e-mail:wkc@arches.ngaedu.

PSPB, Vol. 28 No. 3, March 2002 358-368

(C) 2002 by the Society for Personality and Social Psychology, Inc. 
Scherer, K. R. (1986). Vocal affect expression: A review and a model for future research. Psychological Bulletin, 99, 143-165.

Strauman, T J., Lemieux, A. M., \& Coe, C. L. (1993). Self-discrepancy and natural killer cell activity: Immunological consequences of negative self-evaluation. Journal of Personality and Social Psychology, 64, 1042-1052.

Streeter, L. A., MacDonald, N. H., Apple, W., Kraus, R. M., \& Galati, K. M. (1983). Acoustic and perceptual indicators of emotional stress. Journal of the Acoustical Society of America, 73, 1354-1360.

Taylor, S., Klein, L. C., Lewis, B. P., Gruenwald, T., et al. (2000). Biobehavioral responses to stress in females: Tend-and-befriend, not fight-or-flight. Psychological Review, 107, 411-429.

Tomakaj, Blascovichj, Kiblerj, \& Ernst, J. M. (1997). Cognitive and physiological antecedents of threat and challenge appraisal. Journal of Personality and Social Psychology, 73, 63-72.

Wolkowitz, O. M., Reus, V I., Weingartner, H., Thompson, K., et al. (1990). Cognitive effects of corticosteroids. AmericanJournal ofPsychiatry, 147,1297-1303.
Worden, F., \& Galambos, R. (1972). Auditory processing of biologically significant sounds. Neurosciences Research Program Bulletin, 10 $1-117$.

Zebrowitz, L. A. (1997). Readingfaces. Boulder, CO: Westview.

Zebrowitz, L. A., \& Montepare, J. M. (1992). Impressions of babyfaced males and females across the lifespan. DevelopmentalPsychology, 28 , 1143-1152.

Zeskind, P. S., \& Collins, V (1987). Pitch of infant crying and caregiver responses in a natural setting. Infant Behavior and Development, 10, 501-504.

Zorrilla, E. P., DeRubeis, R. J., \& Redei, E. (1995). High self-esteem, hardiness and affective stability are associated with higher basal pituitary-adrenal hormone levels. Psychoneuroendocrinolgy, 20,591601.

Received April 11, 2001

Revision accepted June 1, 2001 
and the Rosenberg Self-Esteem Scale (RSE) (Rosenberg, 1965). Before presenting our methodological procedures in detail, we will review briefly the relevant literature on self-concept biases, narcissism, and self-esteem.

Self-Concept Biases

Researchers have identified two primary types of selfdeceptive biases, an egoistic bias and a moralistic bias (Paulhus \&John, 1998). These two biases reflect either an agentic or a communal value system-loosely speaking, a concern either with social dominance or social connection. An egoistic bias is part of an agentic value system and includes inflated self-views in the domains of extraversion, openness, and intelligence. A moralistic bias is part of a communal value system and includes inflated self-views in the domains of agreeableness, conscientiousness, and morality. Paulhus and John (1998) described these two patterns of value systems and biases at a more general level as alpha and gamma constellations. The present research is an extension of this theoretical approach for the comparison of narcissists and HSE individuals.

Narcissism

Characterization. The personality dimension of narcissism is derived from the clinical criteria for narcissistic personality disorder, but as applied to a normal population (for reviews, see Emmons, 1987; Morf \& Rhodewalt, in press; Rhodewalt \& Morf, 1995). Narcissists are characterized by a highly positive or inflated self-concept. Narcissists use a range of intrapersonal and interpersonal strategies for maintaining positive self-views. For example, narcissists fantasize about fame or power (Raskin \& Novacek, 1991), respond to critical feedback with anger and self-enhancing attributions (Campbell, Reeder, Sedikides, \& Elliot, 2000; Far-well \& Wohlwend-Lloyd, 1998; Rhodewalt \& Morf,1996), and derogate those who provide threatening feedback (Kernis \& Sun, 1994). In addition, narcissists have interpersonal relationships that lack in commitment and caring (Campbell, 1999; Campbell \& Foster, 2001). On the Five Factor Model (FFM) of personality, narcissism is related most consistently to extraversion. However, there is also some evidence that narcissism is related positively to openness/intellectance and negatively to neuroticism and agreeableness (Bradlee \& Emmons, 1992; Costa \& Widiger, 1994; Hendin \& Cheek, 1997; Rhodewalt \& Morf, 1995).

Self-concept positivety. As noted above, narcissists' selfviews should reflect high agency and low communion. Past research is largely consistent with this view. Narcissists perceive themselves to be more intelligent (Gabriel, Critelli, \& Ee, 1994) and creative (Raskin \& Shaw, 1988) than nonnarcissists. They exhibit defensive self-esteem such that they seek admiration but not acceptance (Raskin,
Novacek, \& Hogan, 1991a). They also manifest a somewhat unstable self-esteem (Rhodewalt, Madrian, \& Cheney, 1998). Furthermore, narcissists score highly on the SelfAttributes Questionnaire (SAQ) (Rhodewalt \& Morf, 1995), although this measure makes it difficult to distinguish egoistic and moralistic biases. This pattern of selfaggrandizement also can be observed in experiments that involve interdependent (i.e.,joint outcomes) tasks and experimenter-provided feedback on agentic traits (e.g., creativity) (Sedikides, Campbell, Reeder, \& Elliot, 1998). On such tasks, narcissists report that their perfor-. mance is superior to that of their partners, regardless of whether they work in dyads (Campbell et al., 2000; Far-well \& Wohlwend-Lloyd, 1998) or small groups (Gosling,John, Craik, \& Robins, 1998; John \& Robins, 1994). Finally, in the self-deception literature, narcissism has been linked to an egoistic bias and, specifically, the FFM traits of extraversion and openness (Paulhus \& John, 1998). In summary, the key theme underlying these findings is an agency orientation on that part of narcissists.

The interpersonal dimension. The relation between narcissism and variables associated with interpersonal relatedness is negative. Narcissists express a relatively low desire for many aspects of interpersonal relatedness. This is evident in a lower need for intimacy (Carroll, 1987) and succorance (Raskin \&Terry, 1988). Narcissists are also less empathetic in their relationships (Watson, Grisham, Trotter, \& Biderman, 1984). Likewise, narcissists report enhanced levels of agency (Bradlee \& Emmons, 1992), dominance (Bradlee \& Emmons, 1992; Emmons, 1984; Raskin, Novacek, \& Hogan, 1991b; Raskin \& Terry, 1988), power (e.g., Carroll, 1987), machiavellianism (McHoskey, 1995), and competitiveness (Raskin \& Terry, 1988). Clearly, narcissists are unlikely to desire relationships as a source of intimacy (Sedikides, Campbell, Reeder, Elliot, \& Gregg, in press). Indeed, narcissists are low on communal orientation, a pattern that reflects less selfdeception on such traits as agreeableness, conscientiousness, and morality (Paulhus \&John, 1998).

Does this mean that narcissists are loners or recluses? This is likely not the case. Narcissists do desire contact with others; however, the purpose behind this contact is largely the enhancement of the narcissists' self via admiration, dominance, and competitiveness (Sedikides et al., in press). Narcissists are judged as sociable (e.g., "entertaining" and "not boring;" Paulhus, 1998, Study 2, Time 1) and energetic (Raskin \& Terry, 1988). Also, narcissists report relatively low levels of social anxiety (Watson \& Biderman, 1994) and they do not differ reliably from nonnarcissists on loneliness (Rudich \& Sedikides, 2001). In addition, narcissists are high in sensation-seeking (Emmons, 1991) and report (and are judged to have) elevated levels of exhibitionism and attention- 
seeking (Buss \& Chiodo, 1991; Raskin \& Terry, 1988; Rudich, 1999).

This approach to interpersonal relationships is well illustrated in narcissists' romantic relationships. Narcissists are attracted to admiring and highly positive individuals who will enhance the narcissists' sense. of self-worth either directly via praise or indirectly via identification (e.g., a "trophy spouse"). Narcissists are less attracted to caring individuals (Campbell, 1999) . Once in a romantic relationship, a similar self-serving pattern can be observed. Relative to nonnarcissists, narcissists report less commitment in ongoing romantic relationships. This is largely a result of narcissists' increased attention to alternative dating partners (Campbell \& Foster, 2001). Likewise, narcissists' love styles reflect greater game-playing and more selfishness (Campbell, Foster, \& Finkel, 2001). These particular patterns of behavior in romantic relationships are not characteristic of HSE individuals.

To summarize, we anticipate that narcissists will have positive self-views in domains reflecting agency (e.g., extraversion, openness, intellectance). In contrast, narcissists will not report inflated self-views in domains reflecting a communal orientation (e.g., agreeableness, conscientiousness, and morality). This pattern will be evident in narcissists' romantic relationships. Specifically, they are likely to rate themselves as better than their romantic partners.

Self-Esteem

Characterization and self-concept positivity. By definition, HSE individuals evaluate themselves positively. Furthermore, this positive self-evaluation will be reflected in both agentic and communal domains. HSE individuals are generally confident, gravitating toward leadership positions (Rosenberg, 1965). In contrast, low-self-esteem individuals have a lesser (although not necessarily highly negative) opinion of themselves (Baumeister, Tice, \& Hutton, 1989). In fact, low-self-esteem individuals have certain areas in which they believe that they excel but are otherwise somewhat lacking in confidence (Pelham, 1993). On the FFM, self-esteem is correlated positively with the factors of extraversion, conscientiousness, and openness/intellectance. Self-esteem also correlates negatively with neuroticism (Jackson \& Gerard, 1996). Furthermore, self-esteem has been linked to a general selfenhancement bias derived from self-ratings on traits representing the FFM (Sinha \& Krueger, 1998). Interestingly, narcissism did not correlate with this self-enhancement bias in the Sinha and Krueger (1998) study when self-esteem was controlled.

The interpersonal dimension. High self-esteem is linked to several positive relational outcomes. For example, the positive link between self-esteem and interpersonal relatedness is a central tenet of the sociometer model of self- esteem (Leary Tambor, Terdal, \& Downs, 1995). Individuals with low self-esteem also may be more socially needy than HSE individuals (Rudich \& Vallacher, 1999).

When examining romantic relationships, the influence of self-esteem is complex (Campbell \& Baumeister, 2001). HSE individuals typically have positive evaluations of their romantic partners that may, in turn, result in relationship satisfaction (Murray, Holmes, \& Griffin, 1996a, 1996b). HSE individuals also report less mania or "lovesickness" in their romantic relationships (Campbell et al., 2001; Hendrick \& Hendrick, 1986). In contrast, low-self-esteem individuals engage in reassuranceseeking behaviors in romantic relationships, especially when they are depressed (Joiner, Alfano, \& Metalsky, 1992). In short, HSE is related to some positive relationship-oriented outcomes and HSE individuals are not as socially needy as low-self-esteem individuals.

To summarize, we anticipate that HSE individuals will have positive self-views in domains reflecting agency (e.g., extraversion, openness, intellectance) as well as those reflecting a communal orientation (e.g., agreeableness, conscientiousness, morality). This pattern will be - evident in HSE individuals' romantic relationships. Specifically, HSE individuals are likely to refrain from rating themselves as better than their romantic partners.

\section{The Present Research}

The primary goal of the present research is to distinguish between the self-concepts of narcissists and HSE individuals. It is clear from the research literature that both narcissists and HSE individuals have positive selfviews. However, we propose that the two groups differ in the specific self-views that they deem to be positive.

If there are differences in the positivity of narcissists' and HSE individuals' self-concepts, where would these differences likely be found? We hypothesize that narcissists view themselves positively primarily in domains reflecting agency (e.g., extraversion, openness, intelligence). That is, they will manifest an egoistic bias. However, narcissists will not display inflated self-views in the domain of communion (e.g., agreeableness, conscientiousness, morality). That is, they will not manifest a moralistic bias. In contrast, HSE individuals perceive themselves to be positive on a range of traits. These will include both agentic and communal traits. Stated otherwise, these individuals will display both an egoistic and a moralistic bias.

In the present research, we relied on a standard and a modified better-than-average effect procedure. This procedure requires individuals to describe their selfconcept by comparing themselves to others on a range of trait terms. We used converging methods to examine self-concept positivity on agentic and communal traits. In Study 1A, we examined the better-than-average effect on a list of positive and negative trait terms taken from 
past research (Alicke, 1985) as well as trait terms derived from the FFM (John, 1990). An agentic bias will be reflected in elevated extraversion and openness to experience/intellectance ratings. A communal bias will be reflected in elevated agreeableness and conscientiousness ratings. In Study 1B, we replicated these findings and also examined the positivity attached to these trait words. In Study 2, we examined self-concept positivity directly in the interpersonal realm. Individuals rated their views of themselves, their romantic partner, and themselves relative to their romantic partner. An agentic bias will be reflected in an inflated view of self compared to the romantic partner. In Study 3, we adopted a procedure associated with the "Muhammad Ali effect" (Allison, Messick, \& Goethals, 1989). Participants described their self-views regarding intelligence and morality. An agentic bias will be reflected in enhanced intelligence ratings, whereas a communal bias will be reflected in enhanced morality ratings. To summarize our hypotheses, narcissists' better-than-average self-views will fall squarely in the domain of agency (i.e., egoistic bias), whereas HSE individuals' self-views will extend into both agency and communal domains (i.e., egoistic and moralistic biases).

\section{STUDY I}

Do narcissists and HSE individuals report having positive yet distinct self-views? In what aspects of the selfconcept, agency or communion, do these positive selfviews reside? We approached these questions by examining traits relevant to aspects of the FFM.

\section{Method}

Participants. In Study IA, 113 undergraduate students (27 men, 86 women) from the University of North Carolina at Chapel Hill (UNC-CH) participated. In Study 1B, participants were 85 UNC-CH undergraduate students. Due to an error in data collection, participant genderwas not recorded in Study 1B and Study 3. In all studies, volunteers received Introductory Psychology course credit and were thoroughly debriefed at the end of the experimental session.

Materials and procedure. After arriving at the experimental room, participants in Study IA completed the RSE scale and the NPI. The form of the RSE that we used contained 10 items that were responded to on a 9-point scale (potential range 10-90). The NPI contained 40 forced-choice items with a potential range of 0 to 40 . Next, participants reported the extent to which they possessed certain traits relative to the average person. Participants rated themselves on 80 traits using a 9-point scale with endpoints at 0 (much less than the averageperson) and 8 (much more than the average person). We adapted this procedure from Alicke (1985). We took 40 of these traits directly from Alicke (1985), with 20 traits expressing positive characteristics (e.g., intelligent, dependable) and another 20 traits expressing negative characteristics (e.g., insecure, complaining). We derived an additional 40 traits from the FFM (John, 1990) factors of extraversion (e.g., energetic, assertive), agreeableness (e.g., cold [reverse-scored], cooperative), conscientiousness (e.g., efficient, organized), neuroticism (e.g., tense, nervous), and openness to experience/intellectance (e.g., clever, intelligent).

In Study 1B, participants completed the same measures and trait ratings as in Study IA. In addition, Study 1B participants rated the positivity of each of these traits using a 9-point scale with anchors at 0 (very negative) and 8 (very positive). We hypothesized that the traits on which narcissists and HSE individuals rate themselves as better than average also will be the traits that they deem to be positive (Alicke,1985; Sedikides, 1993; Sedikides \& Green, 2000).

Results

Descriptive statistics. In Study 1A, means and standard deviations for the variables of interest were as follows: $\operatorname{RSE}(\mathrm{M}=69.38, \mathrm{SD}=13.82, \mathrm{a}=.89), \mathrm{NPI}(\mathrm{M}=15.30, \mathrm{SD}=$ $6.67, \mathrm{a}=.84)$, positive traits $(\mathrm{M}=5.81, \mathrm{SD}=.81, \mathrm{a}=: 90)$, negative traits $(\mathrm{M}=2.93, \mathrm{SD}=.94, \mathrm{a}=.80)$, extraversion ( $\mathrm{M}=4.71, \mathrm{SD}=1.17, \mathrm{a}=.87)$, agreeableness $(M=5.40$, $S D=1.86, \mathrm{a}=.90)$, conscientiousness $(\mathrm{M}=4.99, \mathrm{SD}=.92$, $\mathrm{a}=.70)$, neuroticism $(\mathrm{M}=3.58, \mathrm{SD}=1.03, \mathrm{a}=.81)$, and openness $(M=5.07, \mathrm{SD}=.78, \mathrm{a}=.79)$. The RSE and the NPI were correlated, $r=.22, \mathrm{P}<.05$.

In Study 1B, means and standard deviations for the variables of interest were as follows: $\operatorname{RSE}(\mathrm{M}=73.52, \mathrm{SD}=$ 13.05, $\mathrm{a}=.88)$, NPI $(\mathrm{M}=16.72, \mathrm{SD}=6.59, \mathrm{a}=.83)$, positive traits $(\mathrm{M}=5.93, \mathrm{SD}=.93, \mathrm{a}=.89)$, negative traits $(\mathrm{M}=$ $2.71, S D=1.05,(\mathrm{x}=.90)$, extraversion $(\mathrm{M}=4.85, S D=$ 1.23, $\mathrm{a}=.87)$, agreeableness $(\mathrm{M}=5.85, \mathrm{SD}=.96, \mathrm{a}=.78)$, conscientiousness $(\mathrm{M}=5.18, \mathrm{SD}=1.03, \mathrm{a}=.80)$, neuroticism $(\mathrm{M}=3.40, \mathrm{SD}=1.16, \mathrm{a}=.84)$, and openness $(\mathrm{M}=5.26, \mathrm{SD}=.88, \mathrm{a}=.83)$. The RSE and the NPI were correlated, $r=.24, \mathrm{p}<.05$.

Positive and negative traits. We present all results in Table 1 . This table also contains a combined correlation representing the results from both Study IA and $1 \mathrm{~B}$. As hypothesized, both narcissism and HSE were related significantly to perceiving the self as above average on positive trait terms across both samples. Likewise, self-esteem was related inversely to perceiving the self as above average on negative trait terms (as expected), whereas there was no relation between narcissism and negative trait terms. Thus, both constructs predicted the better-thanaverage effect on positive traits, but only HSE predicted the better-than-average effect on negative traits. (These 
TABLE 1: Narcissism, Self-Esteem, and the Better-Than-Average Effect: Study 1, Samples A and B

\begin{tabular}{ccccc}
\hline & & More & Agency/ \\
NPI & $R S E$ & t Value & Enhancing & Communion \\
\hline
\end{tabular}

\begin{tabular}{|c|c|c|c|c|c|}
\hline \multicolumn{6}{|l|}{ Positive items } \\
\hline Rating A & $.28 *$ & $.37 * *$ & & & \\
\hline Rating B & .15 & $40 * *$ & & & \\
\hline Combined & $22 * *$ & $38 * *$ & $-1.97 *$ & RSE & Both \\
\hline Positivity B & $.29 * *$ & $42 * *$ & & & \\
\hline \multicolumn{6}{|l|}{ Negative items } \\
\hline Rating A &.$- \mathrm{O} 1$ & $-.40 * *$ & & & \\
\hline Rating B & .08 & $-.48 * *$ & & & \\
\hline Combined & .03 & $-.43 * *$ & $5.80^{* *}$ & RSE & Both \\
\hline Positivity B & -.06 & $-.26 *$ & & & \\
\hline \multicolumn{6}{|l|}{ Extraversion } \\
\hline Rating A & $46^{* *}$ & $.34 * *$ & & & \\
\hline Rating B & _58** & $.35^{* *}$ & & & \\
\hline Combined & $.51 * *$ & $.34 * *$ & $2.31 *$ & NPI & Agency \\
\hline Positivity B & $43^{* *}$ & .17 & & & \\
\hline \multicolumn{6}{|l|}{ Agreeableness } \\
\hline Rating A & -.04 & $47 * *$ & & & \\
\hline Rating B & -.17 & $47 * *$ & & & \\
\hline Combined & -.10 & $.47 * *$ & $-7.49 * *$ & RSE & Communion \\
\hline Positivity B & -.11 & $29 * *$ & & & \\
\hline \multicolumn{6}{|c|}{ Conscientiousness } \\
\hline Rating A & .13 & $.30 * *$ & & & \\
\hline Rating B & .10 & $33^{* *}$ & & & \\
\hline Combined & .12 & $31 * *$ & $-2.25^{*}$ & RSE & Communion \\
\hline PositivityB & .17 & $31 * *$ & & & \\
\hline \multicolumn{6}{|l|}{ Neuroticism } \\
\hline Rating A & -.13 & $-.48 * *$ & & & \\
\hline Rating B & -.17 & $-.65 * *$ & & & \\
\hline Combined & $-.15 *$ & $-.56 * *$ & $5.57 * *$ & RSE & Both \\
\hline Positivity B & -.14 & $-.30 * *$ & & & \\
\hline \multicolumn{6}{|l|}{ Openness } \\
\hline Rating A & $44 * *$ & .14 & & & \\
\hline Rating B & $.37 * *$ & .10 & & & \\
\hline Combined & $.41 * *$ & .12 & $3.38 * *$ & NPI & Agency \\
\hline Positivity B & $44 * *$ & .18 & & & \\
\hline
\end{tabular}

NOTE: RSE $=$ Rosenberg Self-Esteem Scale, NPI = Narcissistic Personality Inventory. Combined refers to the combined $r$ across samples A and B. More enhancing is the group (narcissists, high-self-esteem individuals) that exhibited more self-enhancement. Agency/communion refers to the type o£ trait.

$* \mathrm{P}<.05$. ** $\mathrm{p}<.01$.

findings were not qualified by gender, with the exception that the link between self-esteem and positive traits and neuroticism was stronger for women than for men.)

Next, we compared the correlations involving narcissism and self-esteem both for positive and negative traits (Cohen \& Cohen, 1983). In both cases, HSE individuals reported a more positive self-concept than narcissists. Finally, the trait positivity rating paralleled the betterthan-average ratings.

FFM traits. We display the FFM results also in Table 1. As hypothesized, narcissism was associated significantly with the better-than-average effect for extraversion and openness to experience. Both of these factors reflect an agency orientation. Likewise, there was no relation between narcissism and the factors representing communal orientation (i.e., agreeableness and conscientiousness). Narcissists did not think that they were better than average on these traits. Finally, there was only a small negative correlation between narcissism and reported betterthan- average neuroticism. This overall pattern of results was consistent across the two samples. Finally, the trait positivity rating paralleled the better-than-average ratings in all but one instance.

Also in line with the hypotheses, correlations revealed that self-esteem was related positively to perceiving the self as (a) better than average on the two communal factors (i.e., agreeableness and conscientiousness) and one of the two agency factors (i.e., extraversion) and (b) below average on neuroticism. HSE individuals considered themselves better than average on both communal and agentic traits.

Next, we compared the self-views of narcissists and HSE individuals (Table 1). Narcissists, relative to HSE individuals, displayed a better-than-average effect on agentic traits. In contrast, HSE individuals, relative to narcissists, showed a better-than-average effect on communal traits.

\section{Discussion}

Both narcissists and HSE individuals have positiveyet distinct-self-views. When measured with a list of unspecified traits, HSE individuals appear to have more positive self-concepts than narcissists. The reasons for this difference become clear when a researcher examines the better-than-average effect on traits that reflect the FFM. Narcissists' self-superiority beliefs were limited primarily to those traits that reflect agency, specifically extraversion and openness. On these traits, narcissists displayed a larger better-than-average effect than HSE individuals. In contrast, HSE individuals' self-superiority beliefs expanded on the complete range of traits: agentic, communal, and in between (i.e., neuroticism). Indeed, HSE individuals reported a larger better-thanaverage effect than narcissists on all but the two agentic traits.

Two findings were unexpected. Narcissism was unrelated to the better-than-average effect on general negative traits. Perhaps this finding is an artifact of the composition of the word list. In particular, the positive traits contained several items regarding intelligence (i.e., agentic traits), whereas the negative traits were more communal. Also unexpected was the lack of correlation between HSE and self-rating on traits that denoted openness to experience. Nevertheless, this correlation was in the expected positive direction. A replication is needed. 
STUDY 2

In Study 2, we examined the self-views of narcissists and HSE individuals using a different approach. Specifically, we examined the degree to which narcissists and HSE individuals in ongoing romantic relationships were willing to (a) rate their current romantic partner as better than average and (b) rate themselves as better than their current romantic partner. We hypothesized that narcissists will express a positive view of themselves compared to the average other and, more important, that theywill perceive the self as superior to their current romantic partner. In contrast, we hypothesized that HSE individuals will express a positive view of themselves compared to average others but that they will not rate the self as superior to their romantic partner. These hypotheses reflect the difference in orientations between narcissists and HSE individuals. If narcissists have an agentic but noncommunal orientation, their positive self-views will not be attenuated when the comparison is a romantic partner. In contrast, if HSE individuals have both agentic and communal self-views, they will be willing to temper their positive self-views when the comparison is a close other.

\section{Method}

Participants. One hundred undergraduate students (50 men, 50 women) from Case Western Reserve University volunteered for the study. (None of the results was qualified by gender.) All participants were currently involved in a romantic relationship. We collected these data as part of a larger study of narcissism and romantic relationships.

Procedure. First, participants completed the RSE and NPI. Next, they rated themselves compared to the average person on 10 positive and 10 negative personality traits, which represented a subset of those thatwe used in Studies 1 and 2. Participants also compared their romantic partner to the average person on these 20 traits. Finally, participants rated themselves in comparison to their romantic partner on the 20 traits. Unlike Study 1, the 9-point rating scale in Study 2 ranged from -4 to +4 , with 0 as the midpoint. We modified the range of the scale to make salient the comparison between the self and the partner.

Results and Discussion

Descriptive statistics. Means and standard deviations for the variables of interest were as follows: $\operatorname{RSE}(M=73.95$, $\mathrm{SD}=11.73,(\mathrm{x}=.86), \mathrm{NPI}(\mathrm{M}=17.55, \mathrm{SD}=7.73, \mathrm{a}=.88)$, self versus average person on positive traits $(M=1.65, S D$ $=1.10, \mathbf{a}=.73)$ and on negative traits $(M=-1.02, S D=$ $1.04, a=.72)$, romantic partnerversus average person on positive traits $(\mathrm{M}=1.65, \mathrm{SD}=.94, \mathrm{a}=.82)$ and on negative traits $(\mathrm{M}=-1.19, \mathrm{SD}=.96, \mathrm{a}=.63)$, and selfversus romantic partner on positive traits $(\mathrm{M}=.63, S D=.80, a=.69)$ and on negative traits $(\mathrm{M}=-.00, \mathrm{SD}=.61, a=.46)$. The RSE and the NPI were correlated, $r=.22, \mathrm{p}<.05$. These values are consistent with those of Study 1 .

Self versus average other. We display the results in Table 2. The comparisons of the self to the average other replicated those of Study 1. Both narcissists and HSE individuals reported positive self-views, with HSE individuals being more positive on the negative traits.

Romantic partnerversus average other. How positively do. narcissists and HSE individuals view their romantic partners? Narcissists did not view their romantic partners as better than average on either the positive or the negative traits. In contrast, HSE individuals did view their romantic partners in a positive light, although only when responding to the negative traits. That is, they rated their partners as being below average on negative traits.

Self versus romantic other. We asked participants to rate themselves in relation to their romantic partners. For narcissists, changing the comparison had little effect. Narcissists perceived themselves as better than their romantic partners on positive traits $(r=.48$ vs. .41 for self better-than-average other). In contrast, HSE individuals' better-than-average effect disappeared when the target was their romantic partner rather than an average other.

In summary, this examination of self-views in romantic relationships reveals an interesting theme. Befitting a primarily agentic orientation, narcissists hold positive self-views in limited areas (i.e., those represented by the positive trait terms) and are willing to maintain these self-views even at the cost of derogating their own romantic partners. In contrast, consistently with a less agentic and a more communal orientation, HSE individuals' positive self-views are shared with a romantic partner. We should note that these findings, although in line with much empirical work on "normal" narcissists, may counter some clinical research that has noted romantic idealization on the part of narcissists (e.g., Kernberg, 1974). Assuming that the clinical insights are valid, there are at least two resolutions to this discrepancy. First, it is possible that that there is an early and highly transitory idealization stage on the part of narcissists that our measures did not detect. Second, narcissists' idealized beliefs about romantic partners may be evident in only a small subgroup of narcissists or in a subgroup of relationships. The presence of such subgroups may not have been sufficient in our sample to affect our results.

STUDY 3

In Study 3, we attempted to gain another perspective on the self-views of narcissists and HSE individuals by 
TABLE 2: Narcissism, Self-Esteem, and the Better-Than-Average Effect in Romantic Relationships: Study 2

More IVPI RSE t Value Enhancing

\begin{tabular}{|c|c|c|c|c|}
\hline \multicolumn{5}{|c|}{ Self versus average other } \\
\hline Positive items & $41 * \star$ & $27 * *$ & 1.24 & - \\
\hline Negative items & -.05 & $-.45 * \star$ & $3.54 *$ & RSE \\
\hline \multicolumn{5}{|c|}{$\begin{array}{l}\text { Romantic partner versus } \\
\text { average other }\end{array}$} \\
\hline Positive items & -.03 & 12 & -1.19 & - \\
\hline Negative items & -.03 & $-.35 \star \star$ & $2.70 *$ & RSE \\
\hline \multicolumn{5}{|c|}{ Self versus romantic partner } \\
\hline Positive items & $48^{* *}$ & .06 & $3.78 * *$ & NPI \\
\hline Negative items & -.06 & -.18 & .96 & - \\
\hline
\end{tabular}

NOTE: RSE = Rosenberg Self-Esteem Scale, NPI = Narcissistic Personality Inventory. More enhancing is the group (narcissists, high-selfesteem individuals) that exhibited more self-enhancement. $* \mathrm{p}<.05$.** $\mathrm{p}<.01$.

examining the "Muhammad Ali effect." According to this effect, people believe that they are more moral, but not more intelligent, than the average person (Van Lange, 1991; Van Lange \& Sedikides, 1998; Sedikides \& Strube, 1997). For the purpose of the present investigation, this effect serves as a technique to pit directly agentic (i.e., intelligence) against communal (i.e., morality) aspects of the self.

Indeed, the Muhammad Ali effect is particularly appropriate for examining agentic and communal self-views. Consistently with Paulhus and john's (1998) theorizing, intelligence will clearly reflect an egoistic bias, whereas morality will by definition reflect a moralistic bias. As such, we hypothesize that narcissists will rate themselves as better than average on intelligence (an agentic trait) but not on morality (a communal trait). In contrast, HSE individuals will rate themselves as better than average on both traits.

Method

Materials andprocedure. Participants were 109 UNC- CH undergraduates who completed the RSE and NPI and then reported the degree to which they thought they were better than average on traits that described intelligence and morality. The response format was the same as the one used in Studies 1 and 2. We assessed the degree to which participants reported that they possessed better-than-average intelligence by using 11 traits, such as intelligent, smart, and bright. We assessed the degree to which participants reported that they possessed better-than-average morality by using 17 traits, such as moral, honest, and deceptive (reverse scored). We combined scores from these scales to form indices of betterthan-average intelligence and morality. We also asked participants to rate the positivity of these traits.

\section{Results and Discussion}

Descriptive statistics. Means and standard deviations for the variables of interest were as follows: $\operatorname{RSE}(M=74.00$, $S D=10.01, a=.81)$, NPI $(M=16.05, S D=6.31, a=.82)$, intelligence traits $(M=6.07, S D=1.04,(x=.90)$, and moral traits $(M=6.85, S D=77, a=.84)$. The RSE and the NPI were correlated, $\mathrm{r}=.36, p<.05$.

Better-than-average intelligence. We display all relevant correlations in Table 3. As hypothesized, both narcissism and self-esteem were associated positively with betterthan-average intelligence. This latter result suggests that the lack of significance found in the correlation between self-esteem and openness to experience/intellectance in Study 1 may reflect a small effect size and lack of statistical power. A statistical test showed that narcissism, when compared to self-esteem, was related to a marginally larger better-than-average effect on intelligence traits.

Better-than-average morality. We observed a different pattern of findings on the morality items (Table 3 ). There was no significant relation between narcissism and better-than-average morality. This pattern is consistent with the hypothesis that narcissists will not report being better than average on communal traits. In contrast, there was a significant positive relation between self-esteem and self-reported morality. Individuals high on self-esteem believed that they were more moral than the average person. When we compared the narcissism and self-esteem correlations, we found that HSE individuals reported a significantly higher better-than-average effect on morality.

In summary, the results of Study 3 supported the hypotheses. Narcissists perceive themselves as being more intelligent (an agentic trait) but not as more moral (a, communal trait) than the average person. HSE individuals tend to see themselves as both more intelligent (although not to the degree that narcissists do) and more moral than the average person.

\section{GENERAL DISCUSSION}

Both narcissists and HSE individuals have positive self-views, as our investigation confirms. More important, it is now clear that the particular self-views on which narcissists and HSE individuals perceive themselves as being better than average differ reliably. To communicate this notion statistically, we meta-analyzed the results of our three studies (Table 4). For each sample, we present the average correlation between narcissism and the agency and communion variables as well as for selfesteem and the agency and communion variables. We operationalize agency in terms of extraversion and openness (Study 1A and 1B), self versus romantic partner (Study 2), and intelligence (Study 3). We operationalize 
TABLE 3: Narcissism, Self-Esteem, and the Muhammad Ali Effect: Study 3

\begin{tabular}{|c|c|c|c|c|c|}
\hline & $1 \mathrm{JPl}$ & $R S E$ & t Value & $\begin{array}{c}\text { More } \\
\text { Enhancing }\end{array}$ & $\begin{array}{c}\text { Agency/ } \\
\text { Communion }\end{array}$ \\
\hline \multicolumn{6}{|l|}{ Intelligence } \\
\hline Rating & $41 * *$ & $23 * *$ & 1.807 & NPI & Agency \\
\hline Positivity & $27 * *$ & .02 & & & \\
\hline \multicolumn{6}{|l|}{ Morality } \\
\hline Rating & -.17 & $.21 *$ & $-3.67 * *$ & RSE & Communion \\
\hline Positivity & -.06 & -.08 & & & \\
\hline
\end{tabular}

NOTE: RSE $=$ Rosenberg Self-Esteem Scale, NPI = Narcissistic Personality Inventory. More enhancing is the group (narcissists, high-self-esteem individuals) that exhibited more self-enhancement. Agency/ communion refers to the type of trait. tp $<.10: * \mathrm{p}<.05 . * * \mathrm{p}<.01$

TABLE 4: Synthesis of Agency and Communion Results Across Studies

$\begin{array}{ccccc}\text { Study } & \text { Study } & \text { Study } & \text { Study } & \text { Combined, } \\ 1 A & 1 B & 2 & 3 & \text { ci } 95 \%\end{array}$

Narcissism (NPI)

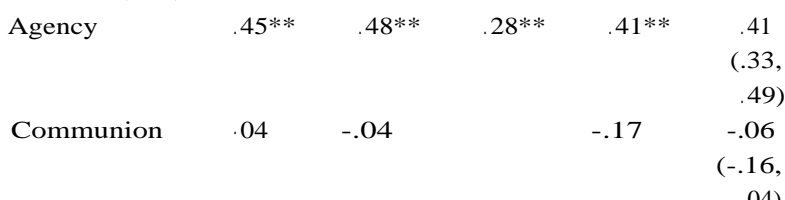

High self-esteem (RSE)

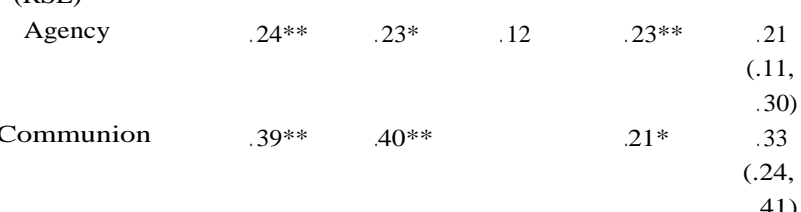

NOTE: RSE $=$ Rosenberg Self-Esteem Scale, NPI = Narcissistic Personality Inventory. Combined $n=407$; cirefers to $95 \%$ confidence interval. Agency is represented by extraversion and openness (Study $1 \mathrm{~A}$ and 1B), self versus romantic partner (Study 2), and intelligence (Study 3). Communion is represented by agreeableness and conscientiousness (Study IA and 1B) and morality (Study 3).

$* p<.05 . * * p<.01$.

communion in terms of agreeableness and conscientiousness (Study IA and 1B) and morality (Study 3). (Across the three studies, the average correlation between narcissism and self-esteem was .26.)

The pattern of results is remarkably consistent across studies. Narcissists perceive themselves as better than average on traits reflecting agency but do not perceive themselves as better than average on traits reflecting communion. In contrast, HSE individuals perceive themselves as better than average on both agency and communion traits. Furthermore, an inspection of the confidence intervals around the combined correlations sug- gests that narcissists' better-than-average views on agency traits (combined $r=.41$ ) are higher than those of HSE individuals (combined $r=.21$ ). Likewise, narcissists' selfviews on communal traits (combined $r=-.06$ ) are lower than those of HSE individuals (combined $r=.33$ ).

Put more simply, narcissists' positive self-opinions rest squarely and strongly in the agency domain, whereas HSE individuals allocate their positive self-opinions equally to the agency and communion domains.

\section{Implications}

What do these findings tell us about the relation between narcissism and HSE? First, narcissism does not appear simply to reflect exceptionally high self-esteem. Indeed, HSE individuals viewed themselves equally to or in a more positive light than did narcissists. Rather, the key differences between these two groups are the facets of the self that each group holds in high regard. Narcissists view themselves as highly outgoing and competent on certain cognitive skills (i.e., agency). These positive beliefs do not transfer to their romantic partners. Also, narcissists are relatively unconcerned with being nice or moral (i.e., communion); that is, they display an extensive egoistic bias but not a moralistic bias. In contrast, HSE individuals view themselves as highly positive on communal traits, such as nice, considerate, conscientious, well-adjusted, and moral. Also, they hold positive views of their romantic partners. In addition, they perceive themselves as more intelligent than others but not to the same extent as do narcissists. In summary, HSE individuals display both an egoistic and a moralistic bias.

These differences in self-conceptions have implications for the interpersonal self-regulatory strategies that the two groups use. Narcissists' positive agentic self-views are expressed through efforts to win admiration and attention from others, often by comparing and competing with others; narcissists see themselves as willing to assert and defend their competence interpersonally. For example, a narcissist who believes that he is intelligent may actively maintain this self-view by publicly exclaiming his own superior skills, derogating the success of others (including even a close other), and seeking situations in which he can compete intellectually with others. Why are narcissists willing to derogate others in the pursuit of individual self-enhancement? Probably because narcissists are not burdened by communal concerns (Sedikides et al., in press).

In contrast, HSE individuals report both egoistic and moralistic biases. Self-regulatory efforts on the part of HSE individuals will thus be aimed at enhancing both agentic and communal traits. This will make it problematic to enhance the self by, for example, comparing the self positively to close others (e.g., Study 2 ). HSE individ- 
uals would like refrain from self-regulatory strategies that inflate egoistic biases at the expense of moralistic biases.

This self-regulatory quandary that is faced by HSE individuals but not by narcissists may be why society smiles on the former and frowns on the latter. Narcissists like themselves in unlikable ways and HSE individuals like themselves in likable ways. One may dislike the narcissist for placing importance on outdoing others and not placing importance on interpersonal caring or morality. In contrast, the HSE individual may be admired for placing importance on prosocial traits. The one domain in which society may admire narcissists is achievement. Individuals may not mind a narcissist on the team if he or she is focused on gaining praise by performing well. Unfortunately, narcissism is problematic even in this domain because the narcissist may view success where there is none or even steal success from his or her colleagues (Farwell \& Wohlwend-Lloyd, 1998; John \& Robins, 1994; Sedikides \& Gregg, 2001). Perhaps another way to distill the difference between narcissists and HSE individuals is that narcissists want to be admired, whereas HSE individuals want to be popular. The latter is less taxing from an interpersonal or societal perspective.

\section{Caveats}

There are several caveats that we must note when discussing the implications of the present research. First, before reaching too far into the behavioral realm, it is important to restate that the focus of the present article is on self-views, not behaviors. Although the self certainly is linked to behavior (Fleury, Sedikides, \& Lunsford, 2001; Sedikides \& Gregg, in press), the self-views of interest may or may not be born out in actual behaviors. Future research may examine behavioral differences between narcissists and HSE individuals on various agentic and communal behavioral self-enhancement strategies.

Likewise, we should note that our use of the betterthan-average effect has limitations. Foremost, it was not possible to distinguish clearly between accurate and illusory self-beliefs. In the past, researchers have confirmed self-inflation on certain beliefs by comparing self-reports to objective measures (e.g., Farwell \& Wohlwend-Lloyd, 1998). Similar approaches would be useful in further clarifying accuracy versus inflation in the self-views of narcissists and HSE individuals.

The degree of self-enhancement that participants report on the better-than-average effect paradigm depends on the ambiguity versus specificity of the traits measured (Dunning \& McElwee,1995). We used a high proportion of ambiguous traits in the present research, and it would be useful to know the extent to which our findings are replicated with specific traits. For example, do narcissists use idiosyncratic definitions of agentic traits?

Finally, our work would have benefited from a more . "pure" measure of communal bias. We relied on several traits (e.g., morality, agreeableness) as proxies for communal self-beliefs. Future research will need to examine the link between narcissism, self-esteem, and self-beliefs on communion.

\section{Conclusion}

There are different ways to love oneself. By comparing the self-views of narcissists and HSE individuals, two of these differences become clear. Seeing the self as extremely outgoing and clever (but not as moral or nice) portrays a very different individual than seeing the self as nice and moral as well as somewhat clever or intelligent. Those who adopt the former view are narcissists, whereas those who adopt the latter view have high self-esteem.

\section{REFERENCES}

Alicke, M. D. (1985). Global self-evaluations as determined by the desirability and controllability of trait adjectives. Journal ofPersonality and Social Psychology, 49, 1621-1630.

Alicke, M. D., Klotz, M. L., Breitenbecher, D. L., Yurak, T. J., \& Vredenberg, D. S. (1995). Personal contact, individuation, and the better-than-average effect. Journal of Personality and Social Psychology, 68, 804-825.

Allison, S. T, Messick, D. M., \& Goethals, G. R. (1989). On being better but not smarter than others: The Muhammad Ali effect. Social Cognition, 7, 275-295.

Baumeister, R. F., Tice, D. M., \& Hutton, D. G. (1989). Self-presentational motivations and personality differences in self-esteem. Journal of Personality, 57, 547-579.

Bradlee, P. M., \& Emmons, R. A. (1992). Locating narcissism within the interpersonal circumplex and the five-factor model. Personality and Individual Differences, 13, 821-830.

Buss, D. M., \& Chiodo, L. M. (1991). Narcissistic acts in everyday life. Journal of Personality, 59, 179-215.

Campbell, W. K. (1999). Narcissism and romantic attraction. Journal of Personality and Social Psychology, 77, 1254-1279.

Campbell, W. K. (2001) . A meta-analysis of the narcissism-self-esteem link. Unpublished manuscript, University of Georgia.

Campbell, W. K., \& Baumeister, R. F. (2001). Is loving the self necessary for loving another? An examination of identity and intimacy. In M. Clark \& G. Fletcher (Eds.), Blackwell handbook of social psychology: Vol. 2. Interpersonalprocesses (pp. 437-456). London: Blackwell.

Campbell, W. K., \& Foster, C. A. (in press). Narcissism and commitment in romantic relationships: An investment model analysis. Personality and Social Psychology Bulletin.

Campbell, W. K., Foster, C. A., \& Finkel, E. (2001). Does self-love lead to love for others? A story of narcissistic game-playing. Unpublished manuscript, University of Georgia.

Campbell, W. K., Reeder, G. D., Sedikides, C., \& Elliot, A. T. (2000). Narcissism and comparative self-enhancement strategies. Journal of Research in Personality, 34, 329-347.

Carroll, L. (1987). A study of narcissism, affiliation, intimacy, and power motives among students in business administration. Psychological Reports, 61, 355-358.

Cohen, J., \& Cohen, P. (1983). Applied multiple regression/correlation analy sis for the behavioral sciences (2nd ed. ). Hillsdale, NJ: Lawrence Erlbaum.

Costa, P. T., \& Widiger, T. A. (1994). Personality disorders and thefivefactormodel ofpersonality. Washington, DC: American Psychological Association. 
Dunning, D., \& McElwee, R. O. (1995). Idiosyncratic trait definitions: Implications for self-description and social judgment. Journal of Personality and Social Psychology, 68, 936-946.

Emmons, R. A. (1984). Factor analysis and construct validity of the narcissistic personality inventory. Journal of Personality Assessment, 48,291-300.

Emmons, R. A. (1987). Narcissism: Theory and measurement.Journal of Personality and Social Psychology, 52, 11-17.

Emmons, R. A. (1991). Relationship between narcissism and sensation seeking. Journal of Social Behavior and Personality, 6, 943-954.

Farwell, L., \& Wohlwend-Lloyd, R. (1998). Narcissistic processes: Optimistic expectations, favorable self-evaluations, and selfenhancing attribution. Journal of Personality, 66, 65-83.

Fleury, J., Sedikides, C., \& Lunsford, V (2001). Women's experience following a cardiac event: The role of the self in healing. Journal of Cardiovascular Nursing, 15, 71-82.

Gabriel, M. T, Critelli,J. W., \& Ee,J. S. (1994). Narcissistic illusions in self-evaluations of intelligence and attractiveness. Journal ofPersonality, 62,143-155.

Gosling, S. D., John, O. P., Craik, K. H., \& Robins, R. W. (1998). Do people know how they behave? Self-reported act frequencies compared with on-line codings by observers. Journal of Personality and Social Psychology, 112, 107-118.

Hendin, H. M., \& Cheek,J. M. (1997). Assessing hypersensitive narcissism: A reexamination of Murray's Narcism Scale. Journal ofResearch in Personality, 31, 588-599.

Hendrick, C., \& Hendrick, S. S. (1986). A theory and method of love. Journal ofPersonality and Social Psychology, 50, 392-402.

Jackson, L. A., \& Gerard, D. A. (1996). Diurnal types, the "big five" personality factors, and other personal characteristics. Journal of Social Behavior and Personality, 11, 273-283.

John, O. P. (1990). The "Big Five" factor taxonomy: Dimensions of personality in the natural language and in questionnaires. In L. A. Pervin (Ed.), Handbook of personality: Theory and research (pp. 66100). NewYork: Guilford.

John, O. P., \& Robins, R. W. (1994). Accuracy and bias in self-perception: Individual differences in self-enhancement and the role of narcissism. Journal of Personality and Social Psychology, 66, 206-219.

Joiner, T. E., Alfano, M. S., \& Metalsky, G. I., (1992). When depression breeds contempt: Reassurance seeking, self-esteem, and rejection of depressed college students and their roommates. Journal of A bnormal Psychology, 101, 165-173.

Kernberg, O. (1974). Barriers to falling and remaining in love. Journal of the American Psychoanalytic Association, 22, 486-511.

Kernis, M. H., \&Sun, C. (1994). Narcissism and reactions to interpersonal feedback. Journal ofResearch in Personality, 28, 413.

Leary, M. R., Tambor, E. S., Terdal, S. K., \& Downs, D. L. (1995). Selfesteem as an interpersonal monitor: The sociometer hypothesis. Journal of Personality and Social Psychology, 68, 518-530.

McHoskey, J. (1995). Narcissism and machiavellianism. Psychological Reports, 77, 755-759.

Morf, C. C., \& Rhodewalt, F (2001). Unraveling the paradoxes of narcissism: A dynamic self-regulatory processing model. Psychological Inqui7y, 12,177-196.

Murray, S. L., Holmes, J. G., \& Griffin, D. W. (I 996a). The benefit of positive illusions: Idealization and the construction of satisfaction in close relationships. Journal of Personality and SocialPsychology, 70, 79-98..

Murray, S. L., Holmes, J. G., \& Griffin, D. W. (19966). The self-fulfilling nature of positive illusions in romantic relationships: Love is not blind, but prescient. Journal of Personality and Social Psychology, 71,1155-1180.

Paulhus, D. L. (1998). Interpersonal and intrapsychic adaptiveness of trait self-enhancement: A mixed blessing? Journal of Personality and Social Psychology, 74,1197-1208.

Paulhus, D. L., \&John, O. P. (1998). Egoistic and moralistic biases in self-perception: The interplay of self-deceptive styles with basic traits and motives. Journal of Personality, 66, 1025-1060.
Pelham, B. W. (1993). On the highly positive thoughts of the highly depressed. In R. F. Baumeister (Ed.), Self-esteem: The puzzle of low self-regard (pp. 183-200). New York: Plenum.

Raskin, R., \& Hall, C. S. (1979) A narcissistic personality inventory. Psychological Reports, 45, 590.

Raskin, R. N., \& Novacek, J. (1991). Narcissism and the use of fantasy. Journal of Clinical Psychology, 47, 490-499.

Raskin, R. N., Novacek, J., \& Hogan, R. (1991 a). Narcissistic, selfesteem and defensive self-enhancement. Journal ofPersonality, 59, 19-38.

Raskin, R. N., Novacek, J., \& Hogan, R. (19916). Narcissistic selfesteem management. Journal ofPersonality and Social Psychology, 60, 911-918.

Raskin, R. N., \& Shaw, R. (1988). Narcissism and the use of personal pronouns. Journal of Personality, 56, 393-404.

Raskin, R. N., \& Terry, H. (1988). A principle components analysis of the Narcissistic Personality Inventory and further evidence of its construct validity. Journal of Personality and Social Psychology, 54, 890-902.

Rhodewalt, F., Madrian, J. C., \& Cheney, S. (1998). Narcissism, selfknowledge organization, and emotional reactivity: The effect of daily experiences on self-esteem and affect. Personality and Social Psychology Bulletin, 24, 75-87.

Rhodewalt, F., \& Morf, C. C. (1995). Self and interpersonal correlates of the narcissistic personality inventory. Journal of Research in Personality, 29, 1-23.

Rhodewalt, F., \& Morf, C. C. (1996). On self-aggrandizement and anger: A temporal analysis of narcissism and affective reactions. Journal of Personality and Social Psychology, 74, 672-685.

Rosenberg, M. (1965). Society and the adolescent self-image. Princeton, NJ: Princeton University Press.

Rudich, E. A. (1999). The Need forAttention Scale. Unpublished manuscript, University of North Carolina at Chapel Hill.

Rudich, E. A., \& Vallacher, R. R. (1999). To belong or to self-enhance? Motivational bases for choosing interaction partners. Personality and Social Psychology Bulletin, 25, 1389-1406.

Sedikides, C. (1993). Assessment, enhancement, and verification determinants of the self-evaluation process. Journal of Personality and Social Psychology, 65, 317-338.

Sedikides, C., Campbell, W. K., Reeder, G., \& Elliot, A. J. (1998). The self-serving bias in relational context. Journal of Personality and Social Psychology, 74, 378-386.

Sedikides, C., Campbell, W. K., Reeder, G., Elliot, A. J., \& Gregg, A. P. (in press). Do others bring out the worst in narcissists? The "Others Exist for Me" illusion. In Y Kashima, M. Foddy, \& M. Platow (Eds.), Self and identity: Personal, social, and symbolic. Mahwah, NJ: Lawrence Erlbaum.

Sedikides, C., \& Green, J. D. (2000). On the self-protective nature of inconsistency/ negativity management: Using the person memory paradigm to examine self-referent memory. Journal of Personality and Social Psychology, 79, 906-922.

Sedikides, C., \& Gregg, A. P. (2001). Narcissists and feedback: Motivational surfeits and motivational deficits. Psychological Inquiry, 12, 237-239.

Sedikides, C., \& Gregg, A. P. (in press). Self matters. In M. A. Hogg \& J. Cooper (Eds.), Sage handbook of social psychology. London: Sage Ltd.

Sedikides, C., \& Rudich, E. A. (2001). It's a matter ofself-esteem: Narcissism as predictor of mental health. Unpublished manuscript, University of Southampton, England, UK.

Sedikides, C., \& Strube, M. J. (1997). Self-evaluation: To thine own self be good, to thine own self be sure, to thine own self be true, and to thine own self be better. In M. P. Zanna (Ed.), Advances in experimental social psychology (Vol. 29, pp. 209-269). New York: Academic Press.

Sinha, R. R., \& Krueger, J. (1998). Ideographic self-evaluation and bias. Journal of Research in Personality, 32, 131-155.

Van Lange, P.A.M. (1991). Being better but not smarter than others: The Muhammad Ali effect at work in interpersonal situations. Personality and Social Psychology Bulletin, 17, 689-693. 
Van Lange, P.A.M., \& Sedikides, C. (1998). Being more honest but not necessarily more intelligent than others: Generality and explanations for the Muhammad Ali effect. European Journal of Social Psychology, 28, 675-680.

Watson, P. J., \& Biderman, M. D. (1994). Narcissistic traits scale: Validity evidence and sex differences in narcissism. Personality and IndividualDifferences, 16, 501-504.
Watson, P. J., Grisham, S. O., Trotter, M. V , \& Biderman, M. D. (1984) Narcissism and empathy: Validity evidence for the narcissistic personality inventory. Journal of Personality Assessment, 45, 159-162.

Received September 6, 2000

Revision accepted june 1, 2001 